\title{
O gênero Styrax L. (Styracaceae) do Estado do Rio de Janeiro. Nervação e epiderme foliares.
}

\section{Antonia Range/ Bastos ${ }^{1}$ \\ Nilda Marquete Ferreira da Silva ${ }^{2}$}

$O$ presente trabalho trata dos caracteres epidérmicos $e$ da nervação foliar das espécies de Styrax L. (Styracaceae), ocorrentes no Estado do Rio de Janeiro.
1 Pesquisadora do Jardim Botânico do Rio de Janeiro e bolsista do CNPq.

2 Pesquisadora do Jardim Botânico do Rio de Janeiro e bolsista do CNPq.
As autoras agradecem ao CNPq e a Maria da Conceição Valente.

\section{Introdução}

Neste trabalho apresentamos um estudo da nervação e epiderme foliar das espécies do gênero Styrax L. (Styracaceae), ocorrentes no Estado do Rio de Janeiro.

Visamos com este estudo fornecer informações auxiliares à taxonomia, anexando mais dados aos caracteres morfológicos e facilitando a identificação de materiais, bem como servir de base para pesquisas paleobotânicas, filogenéticas, ecológicas e outras afins.

\section{Material e métodos}

0 material botânico referente às es pécies estudadas: $S$. acuminata Pohl; $S$. camporum Pohl, $S$. ferruginea Nees et Mart., S. glabratus Schott, S. lancifolia Klotzsch, S. latifolia Pohl, S. leprosus Hook., S. martii Seub. e S. pohlii DC., foi obtido nos herbários do Jardim Botânico do Rio de Janeiro (RB) e Museu Nacional do Rio de Janeiro (R).

Na diafanização empregamos a técnica de Foster (1950) e de Strittmatter (1973) para as folhas mais espessas.

Para o estudo das epidermes, empre- gamos o material de herbário, dissociado pela mistura de Jeffrey (Johansen, 1940).

Nas folhas revestidas de indumento muito denso, aplicamos o método da raspagem da superfície, com o auxílio de uma lâmina a fim de retirar os pêlos, para em seguida dissociar o referido material, mesmo assim não nos foi possível descrever ou desenhar com exatidão as epidermes abaxiais.

Adotamos Fellipe e Alencastro (1966) para a classificação do padrão de nervação.

Para a realização dos desenhos que ilustram o trabalho, usamos o microscópio óptico Carl Zeiss, com sua respectiva câmara clara em diferentes escalas de aumento. $\mathrm{O}$ aspecto geral da folha foi documentado pelo decalque em papel vegetal das fotografias obtidas usando a preparação montada como negativo, em ampliador fotográfico.

\section{Resultados}

Os caracteres observados nas espécies estudadas, foram reunidos no quadro da página seguinte. 


\begin{tabular}{|c|c|c|c|c|c|c|c|c|c|}
\hline Espécies & S. acuminata & $\begin{array}{l}\text { S. camporum } \\
\text { Pohl }\end{array}$ & $\begin{array}{l}\text { S. ferruginea } \\
\text { Nees et Mart. }\end{array}$ & $\begin{array}{l}\text { S. glabratus } \\
\text { Schott }\end{array}$ & $\begin{array}{l}\text { S. lancifolia } \\
\text { Klotzsch }\end{array}$ & $\begin{array}{l}\text { S. latifolia } \\
\text { Pohl }\end{array}$ & $\begin{array}{l}\text { S. leprosus } \\
\text { Hook. }\end{array}$ & $\begin{array}{l}\text { S. martii } \\
\text { Seub. }\end{array}$ & $\begin{array}{l}\text { S. pohlii } \\
\text { DC. }\end{array}$ \\
\hline $\begin{array}{l}\text { Epiderme Ada } \\
\text { xial (vista } \\
\text { frontal) } \\
\end{array}$ & \multicolumn{9}{|c|}{ células poligonais, 4-7 lados; paredes espessas, retas } \\
\hline $\begin{array}{l}\text { Epiderme } \\
\text { Abaxial (vista } \\
\text { frontal) }\end{array}$ & \multicolumn{3}{|c|}{ densamente revestida de pêlos estrelados } & $\begin{array}{l}\text { células poligo- } \\
\text { nais } 4-7 \text { lados; } \\
\text { paredes espessas, } \\
\text { retas, estôma- } \\
\text { tos anomo- } \\
\text { cíticos, pêlos } \\
\text { ausentes. }\end{array}$ & \multicolumn{5}{|c|}{ densamente revestida de pêlos estrelados } \\
\hline Padrão & \multicolumn{9}{|c|}{ Broquidodroma } \\
\hline Bordo & \multicolumn{2}{|c|}{$\begin{array}{l}\text { anastomosado com peque- } \\
\text { nas ramificações. }\end{array}$} & $\begin{array}{l}\text { anastomosado } \\
\text { sem ramifica- } \\
\text { ções. }\end{array}$ & \multicolumn{2}{|c|}{ anastomosado com ramificações } & \multicolumn{4}{|c|}{$\begin{array}{l}\text { anastomosado sem anastomosado com ramificações. } \\
\text { ramificações }\end{array}$} \\
\hline Rede & \multicolumn{2}{|l|}{ laxa } & densa & laxa & \multicolumn{4}{|c|}{ densa } & laxa \\
\hline $\begin{array}{l}\text { Terminação } \\
\text { vascular }\end{array}$ & \multicolumn{9}{|c|}{ simples e múltiplas } \\
\hline Esclerócito & \multicolumn{2}{|c|}{$\begin{array}{l}\text { com esclerocitos acom- } \\
\text { panhando e terminais } \\
\text { em relação aos feixes }\end{array}$} & $\begin{array}{c}\text { com escleró- } \\
\text { citos acompa- } \\
\text { nhando as ter- } \\
\text { minações }\end{array}$ & $\begin{array}{c}\text { com esclerócitos } \\
\text { acompanhando e } \\
\text { terminais em rela- } \\
\text { ção aos feixes }\end{array}$ & \multicolumn{2}{|c|}{$\begin{array}{c}\text { com esclerócitos } \\
\text { acompanhando as } \\
\text { terminações }\end{array}$} & \multicolumn{2}{|c|}{$\begin{array}{l}\text { com esclerócitos } \\
\text { acompanhando os } \\
\text { feixes e terminais }\end{array}$} & \begin{tabular}{|l|} 
com escleró- \\
citos acom- \\
panhando as \\
terminações \\
\end{tabular} \\
\hline Cristais & $\begin{array}{l}\text { idioblastos } \\
\text { cristaliferos } \\
\text { com drusas }\end{array}$ & \multicolumn{2}{|c|}{ ausência } & $\begin{array}{c}\text { série cristalífera } \\
\text { acompanhando } \\
\text { os feixes }\end{array}$ & \multicolumn{4}{|c|}{ ausência } & $\begin{array}{l}\text { série crista- } \\
\text { lífera acom- } \\
\text { panhando os } \\
\text { feixes }\end{array}$ \\
\hline
\end{tabular}

\section{Conclusão}

As espécies do gênero Styrax L. ocorentes no Estado do Rio de Janeiro, apresentam-se homogêneas nos seguintes caracteres: apenas um tipo de nervação foliar. (broquidódromo); terminações vascular simples e múltiplas; bordo anastomosado com ramificações (exceto em $S$. ferruginea Nees et Mart. e S. Iatifolia Klotzch) o aspecto geral da epiderme adaxial é praticamente o mesmo em todas as espécies.

S. acuminata Pohl possui idioblastos cristalíferos com drusas; em $S$. glabratus
Schott e $S$. pohlii DC. o parênquima que acompanha os feixes vasculares apresenta séries cristal íferas.

$O$ indumento que reveste a epiderme abaxial permite separar as espécies da seguinte maneira:

\section{Abstract}

The present paper treats of the epidermis characteres and foliar nervation of the species of Styrax L. (Styracaceae) ocorring in the State of Rio de Janeiro.

\section{Bibliografia}

FELLIPE, G.M. \& ALLENCASTRO F.M.
M.R. de. Contribuição ao estudo da nervação das Compositae dos Cerrados I. Tribus Helenieae, Heliantheae, Inuleae, Mutisieae e Senecionae. An. Acad. Brasil. Cienc. 38 (Suplemento): 125-157, 132 figs. 1966.

FOSTER, A.S. Pratical Plant Anatomy. 228 p. Princeton - New Jersey, D. Van Nostrand. 1950.

JOHANSEN, A.D. Plant microtechique $\mathrm{XI}+523$ p. ilust. McGraw-Hill Book Co. Inc. New York - London. 1940.

STRITTMATTER, C.G.D. Nueva Tecnica de diafanizacion. Bol. Soc. Arg. Bot. 15(1): 126-129. 1973.

\begin{tabular}{|l|l|}
\hline S. glabratus Schott & glabra \\
\hline S. acuminata Pohl & pélos estrelados, 9-16 braços de tamanhos quase iguais. \\
\hline $\begin{array}{l}\text { S. pohlii DC., S. ferruginea Nees et Mart., S. martii } \\
\text { Seub., S. latifolia Pohi }\end{array}$ & pélos estrelados, oi to ou nove braços de tamanhos diferentes. \\
\hline S. camporum Pohl, S. lancifolia Klotzsch & pélos estrelados, nove braços sendo oito curtos e um longo. \\
\hline S. leprosus Hook. & escamas \\
\hline
\end{tabular}




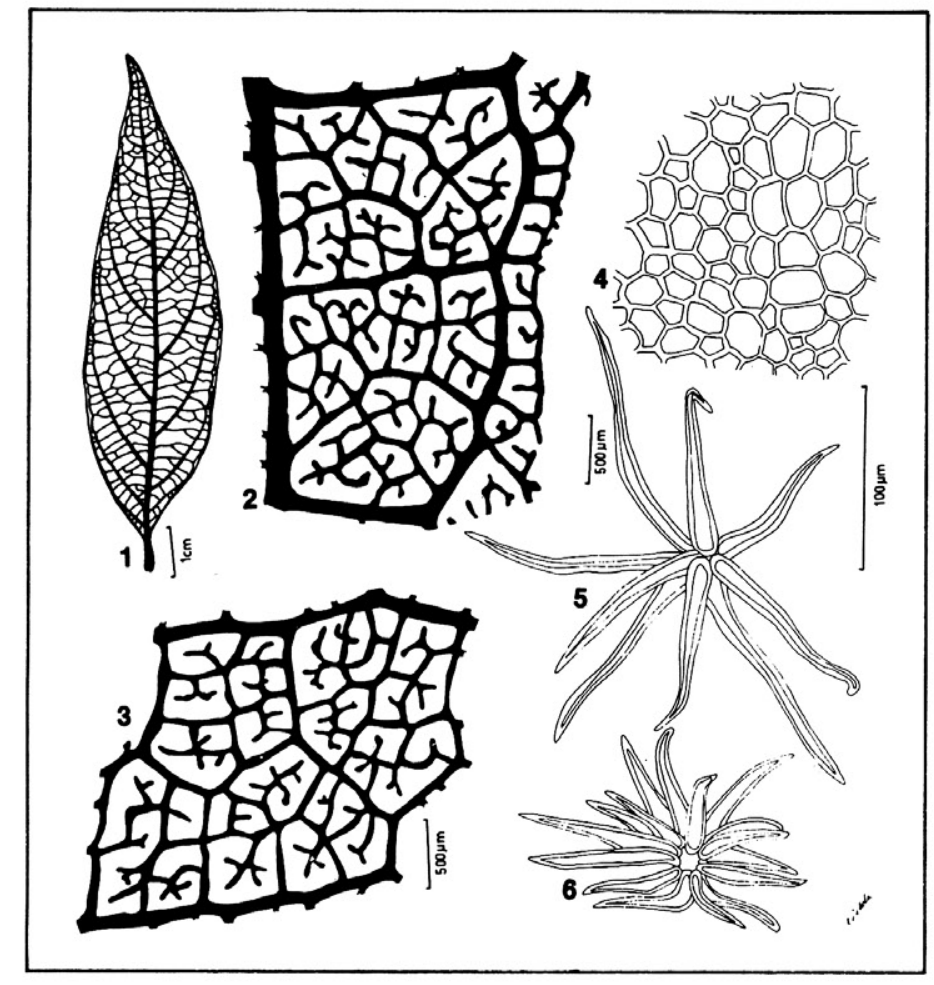

Figura 1

Styrax acuminata Pohl: 1 - aspecto geral da nervação; $\mathbf{2}$ - detalhe do bordo; 3 - detalhe da rede de nervação; 4 - epiderme adaxial em vista frontal; 5 e 6 - pêlos estrelados que revestem a epiderme abaxial.

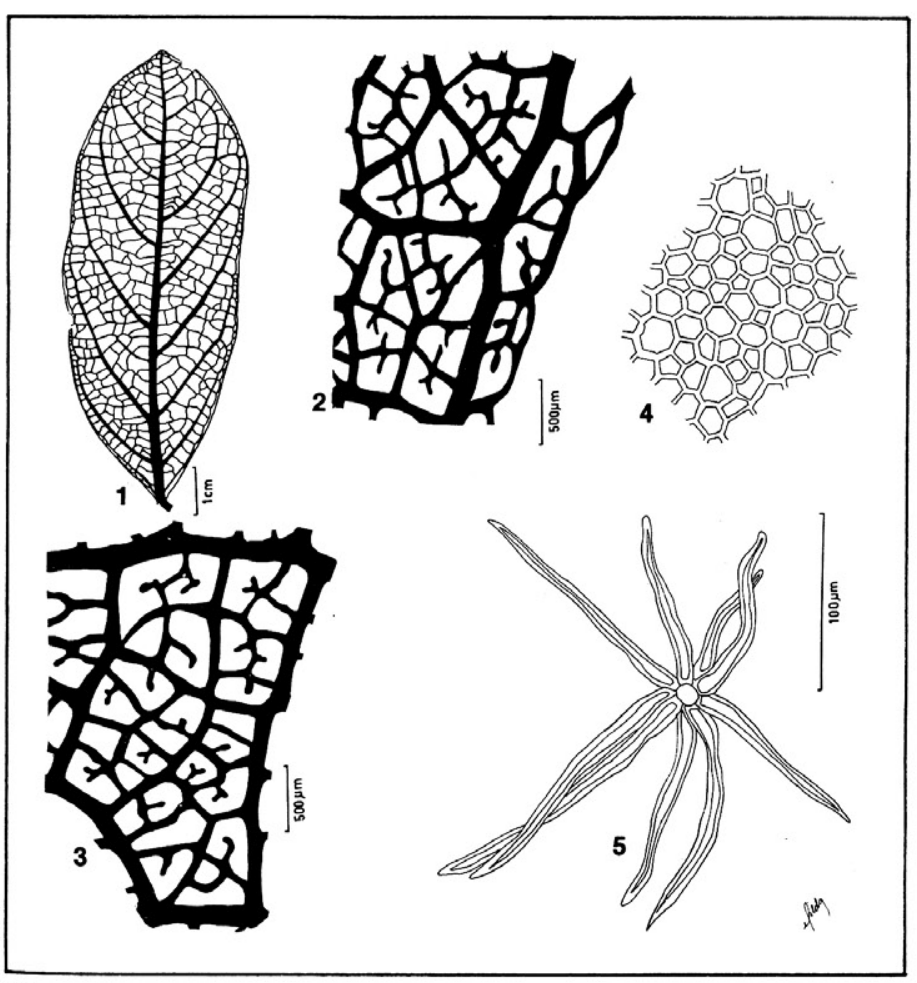

Figura 3

Styrax ferruginea Nees et Mart.: 1 - aspecto geral da nervação; 2 - detalhe do bordo; 3 - detalhe da rede de nervação; 4 - epiderme adaxial, em vista frontal; 5 - pêlo estrelado que reveste a epiderme abaxial.

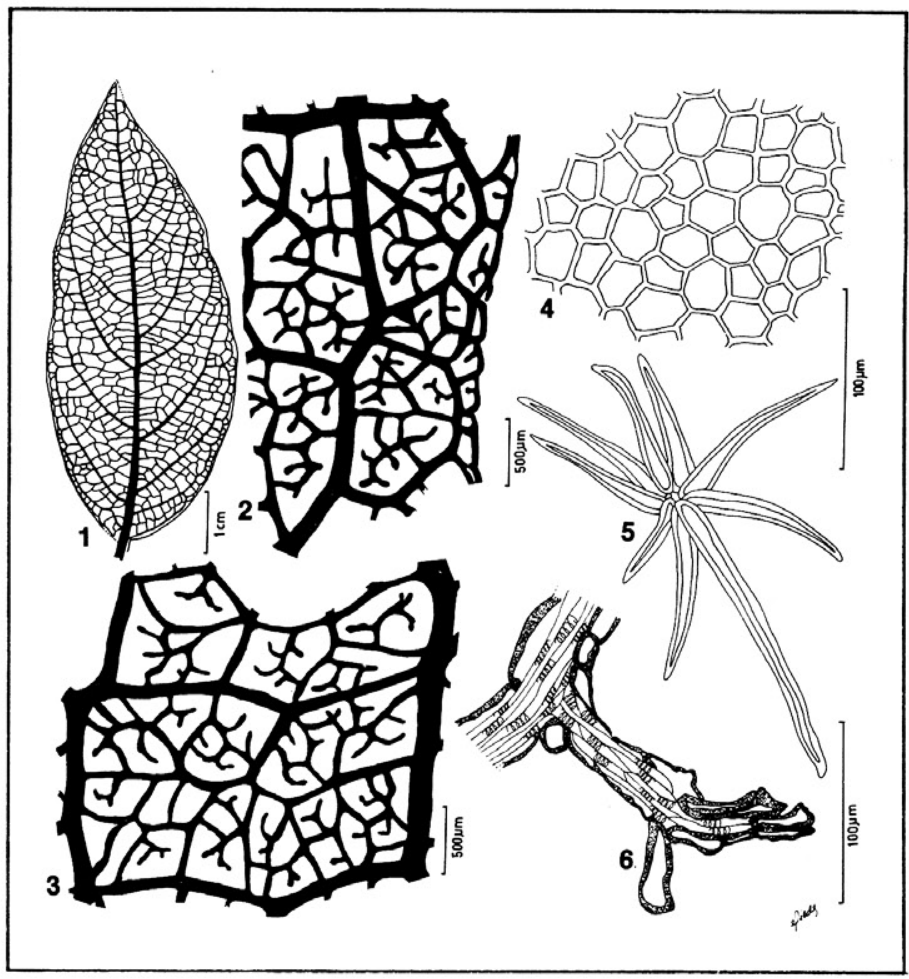

Figura 2

Styrax camporum Pohl: 1 - aspecto geral da nervação; 2 - detaIhe do bordo; 3 - detalhe da rede de nervação; 4 - epiderme adaxial, em vista frontal; 5 - pêlo estrelado que reveste a epiderme abaxial; 6 - terminação vascular evidenciando os esclerócitos.

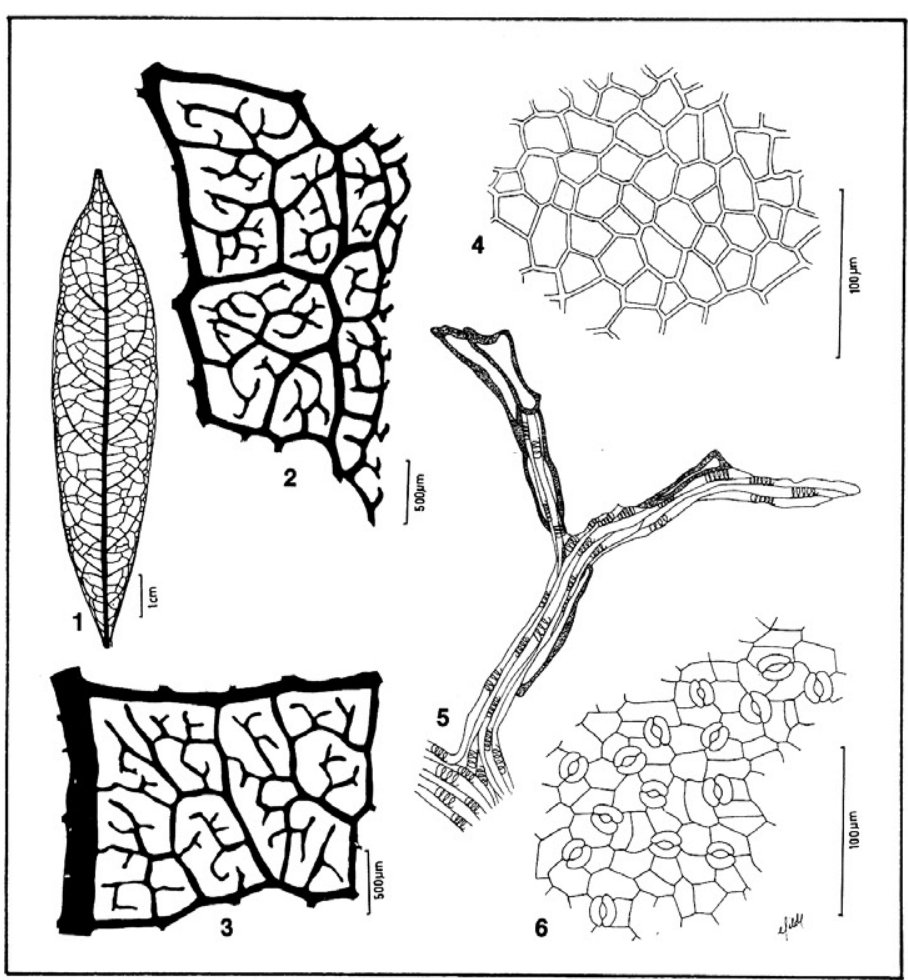

Figura 4

Styrax glabratus Schott: 1 - aspecto geral da nervação; 2 - detaIhe do bordo; 3 - detalhe da rede de nervação; 4 - epiderme adaxial, em vista frontal; 5 - epiderme abaxial evidenciando estomatos anomocíticos; 6 - terminação vascular evidenciando esclerócitos. 


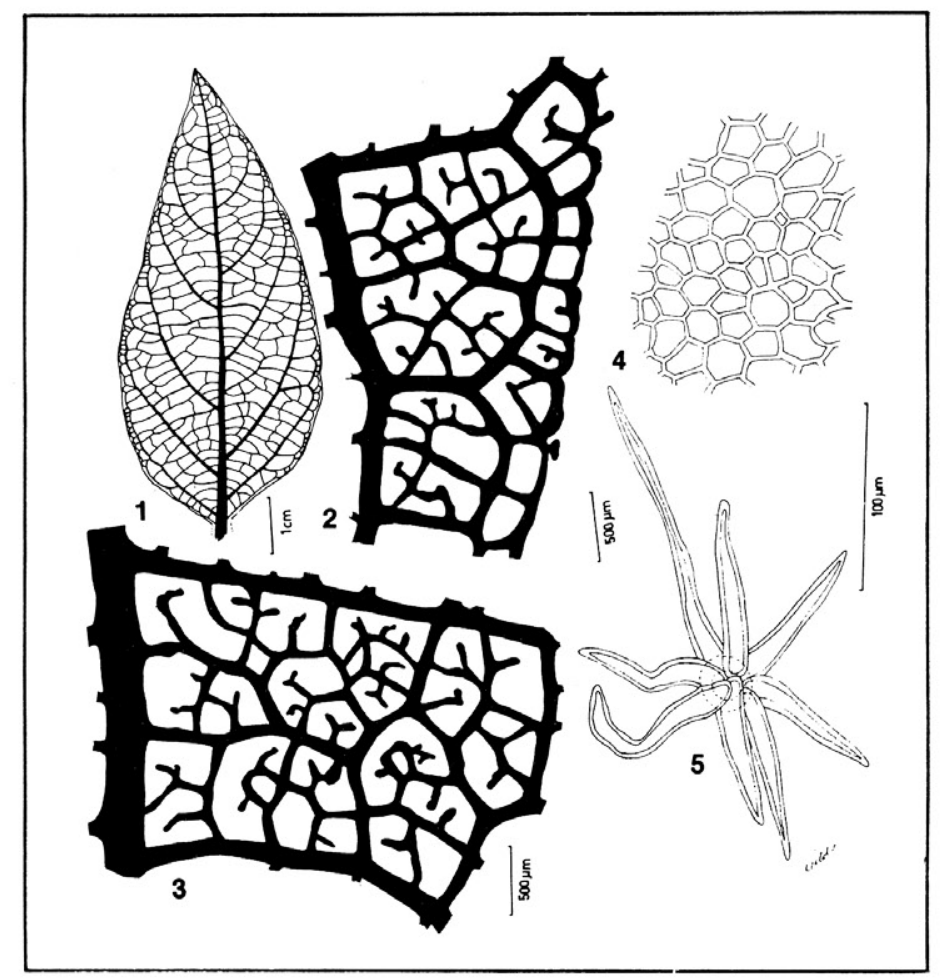

Figura 5

Styrax lancifolia Klotzsch: 1 - aspecto geral da nervação; 2 - detalhe do bordo; 3 - detalhe da rede de nervação; 4 - epiderme adaxial, em vista frontal; 5 - pêlo estrelado que reveste a epiderme abaxial.

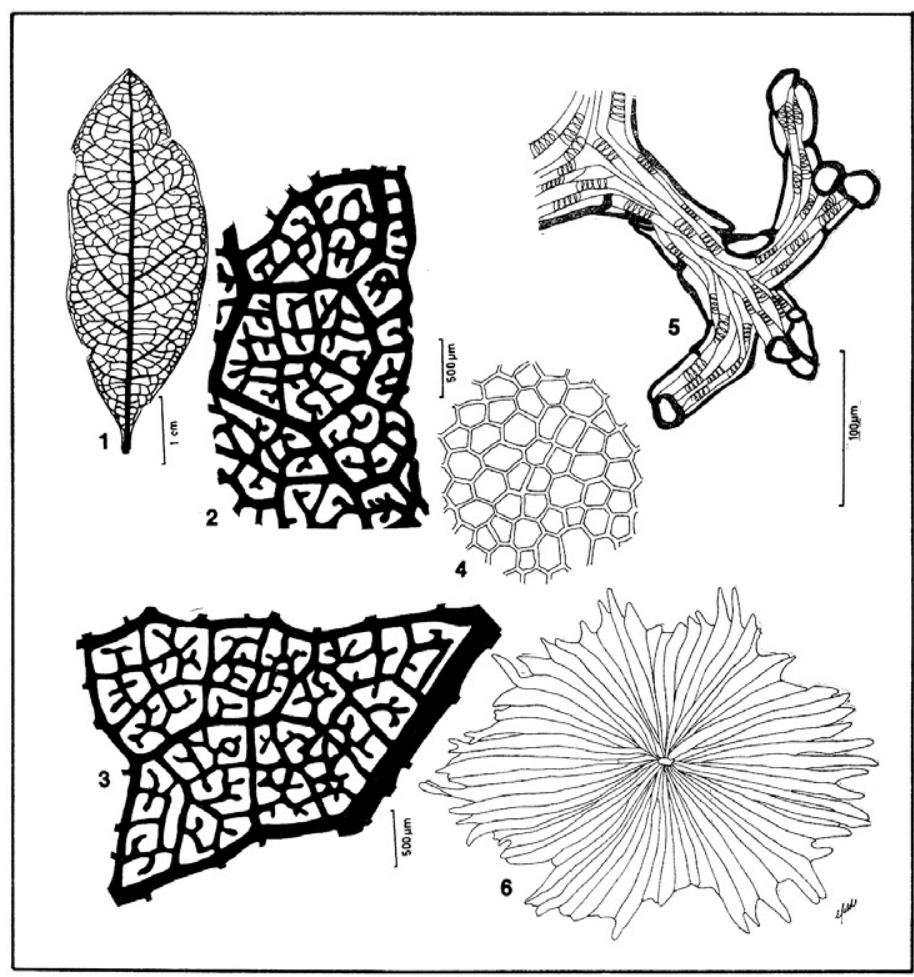

Figura 7

Styrax leprosus Mart.: 1 - aspecto geral da nervação; 2 - detalhe do bordo; 3 - detalhe da rede de nervação; 4 - epiderme adaxial, em vista frontal; 5 - terminação vascular evidenciando esclerócitos; 6 - escama que reveste a epiderme abaxial.

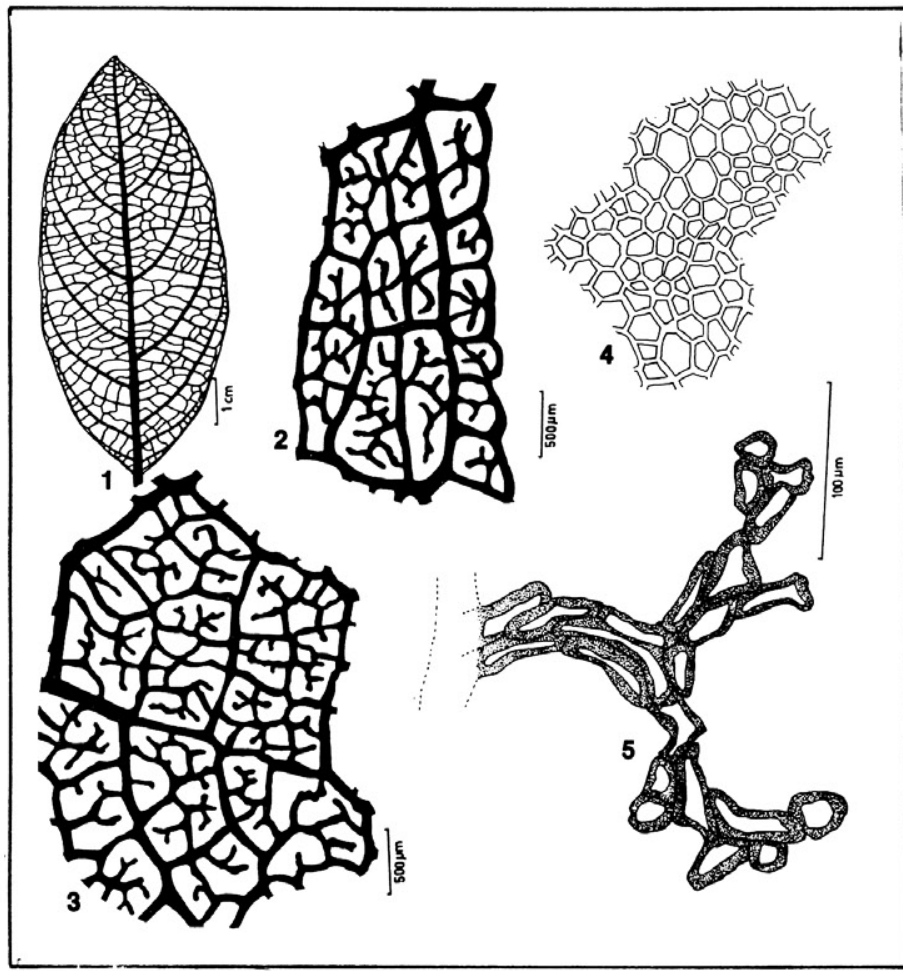

Figura 6

Styrax latifolia Pohl: 1 - aspecto geral da nervação; 2 - detalhe do bordo; 3 - detalhe da rede de nervação; 4 - epiderme adaxial, em vista frontal; 5 - terminação vascular envolvida por esclerócitos.

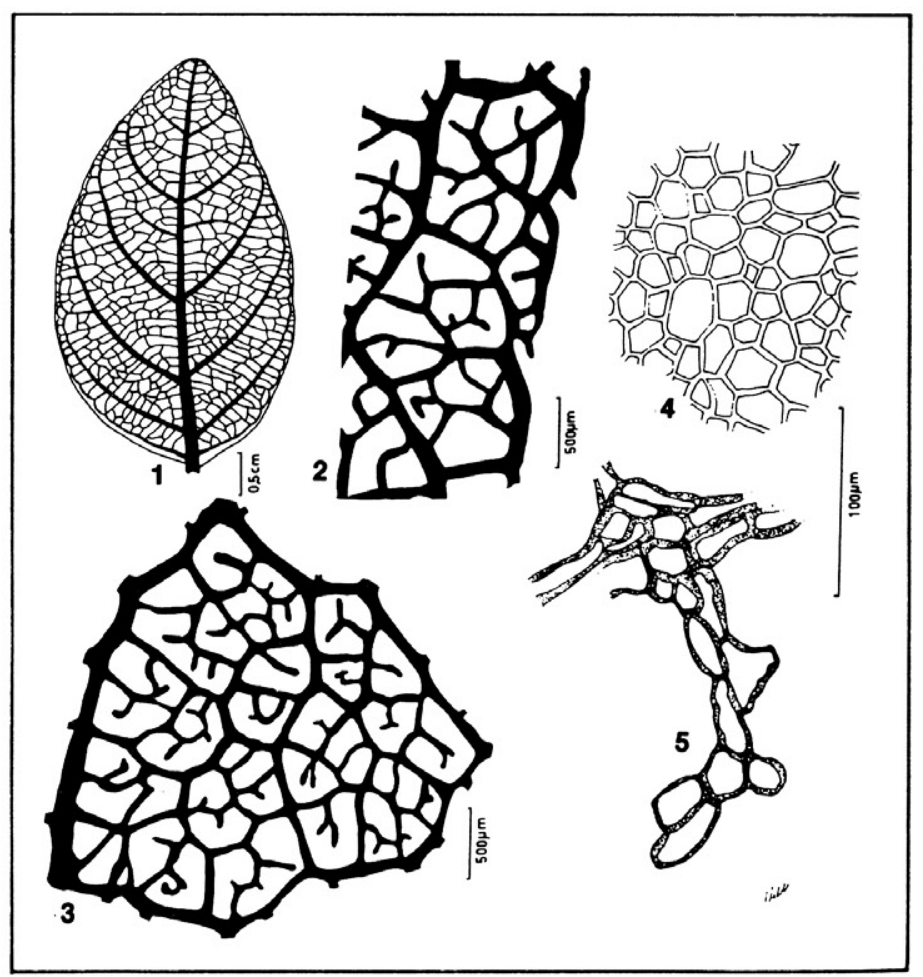

Figura 8

Styrax martii Seub.: 1 - aspecto geral da nervação; 2 - detalhe do bordo; 3 - detalhe da rede de nervação; 4 - epiderme adaxial, em vista frontal; 5 - terminação vascular envolvida por esclerócitos. 


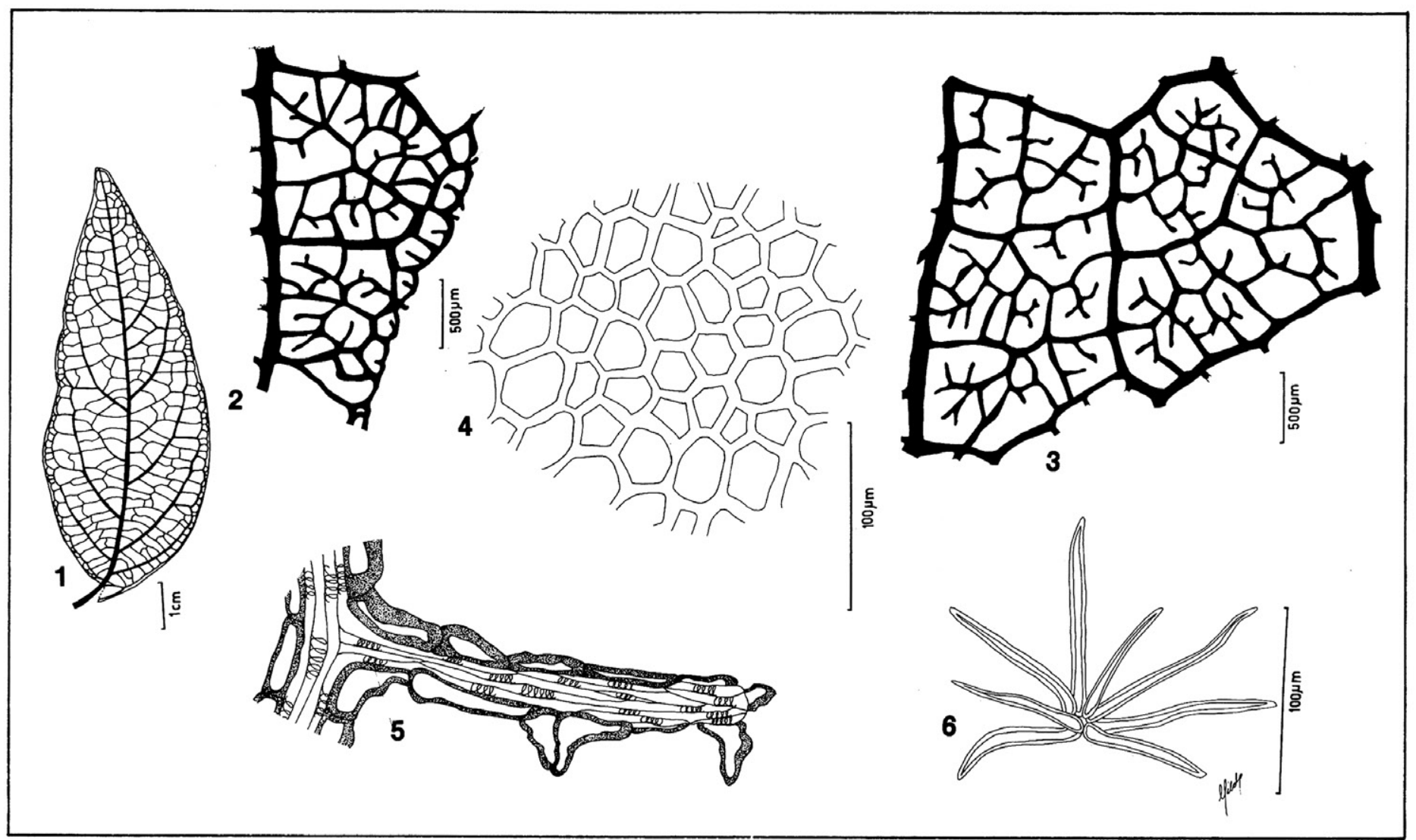

Figura 9

Styrax pohlii DC.: 1 - aspecto geral da nervação; 2 - detalhe do bordo; 3 - detalhe da rede de nervação; 4 - epiderme adaxial, em vista frontal; 5 - terminação vascular evidenciando os esclerócitos; 6 - pêlo estrelado que reveste a epiderme abaxial. 